\title{
Historical perspectives of The American Association for Thoracic Surgery: Adrian V. S. Lambert (1872-1952)
}

\author{
Abe DeAnda, Jr, MD, and Leora B. Balsam, MD
}

Adrian Van Sinderen Lambert (Figure 1), the 22nd president of The American Association for Thoracic Surgery (AATS), was born in New York City on June 30, 1872, the ninth child of Dr and Mrs Edward Wilberforce Lambert. He attended a small private school in New York City and then, like his father and 2 of his older siblings (Samuel Waldron and Alexander), enrolled in Yale University. In addition to the typical premedical curriculum, he also broadened his education to include French, German, and 3 years of Greek. During his junior year, he was "tapped" and inducted into the Skull and Bones secret society, an honor reserved for a select few regarded as campus leaders.

Lambert graduated in 1893 and matriculated at the Columbia University College of Physicians and Surgeons $(\mathrm{P} \& \mathrm{~S})$, following in the footsteps of his father, brothers, and uncle Alfred. He graduated in 1896 and spent a year in a medical internship at New York Hospital. In 1897, he stayed on as a surgical intern, but his internship was interrupted by a freakish accident-his right eye was splashed during a procedure. This led to the development of gonorrheal ophthalmia, which eventually required the enucleation of his eye and resulted in his leaving the residency program.

Heading to Europe, Lambert went to Berlin, Vienna, and Munich to study pathology. He had not given up the thought of being a surgeon, so he learned to adapt to the use of a single eye by cutting meat in a butcher shop as well as performing autopsies and anatomic prosections. Thus, when he returned to New York City at the turn of the century, he was a master anatomist and was able to obtain a position as an assistant demonstrator in anatomy at $\mathrm{P} \& \mathrm{~S}$. His interest in anatomy and pathology was a lifelong pursuit, and he made contributions in the neurosciences, helping to identify some of the cerebral pathways in primates and demonstrating the communication of the cerebral ventricles in wax casts made from cadaveric brains.

In 1904, Lambert became an assistant surgeon in the outpatient service at Bellevue Hospital, and the following year he became an instructor in surgery at P\&S. Although he maintained his academic affiliation with $\mathrm{P} \& \mathrm{~S}$ (eventually

\footnotetext{
From the Department of Cardiothoracic Surgery, New York University-Langone Medical Center, New York, NY.

Address for reprints: Abe DeAnda, MD, Department of Cardiothoracic Surgery, NYU-Langone Medical Center, 530 First Ave, Suite 9V, New York, NY 10016 (E-mail: abe.deanda@nyumc.org).

J Thorac Cardiovasc Surg 2011;141:1344-5

$0022-5223 / \$ 36.00$

Copyright (C) 2011 by The American Association for Thoracic Surgery doi:10.1016/j.jtcvs.2011.01.009
}

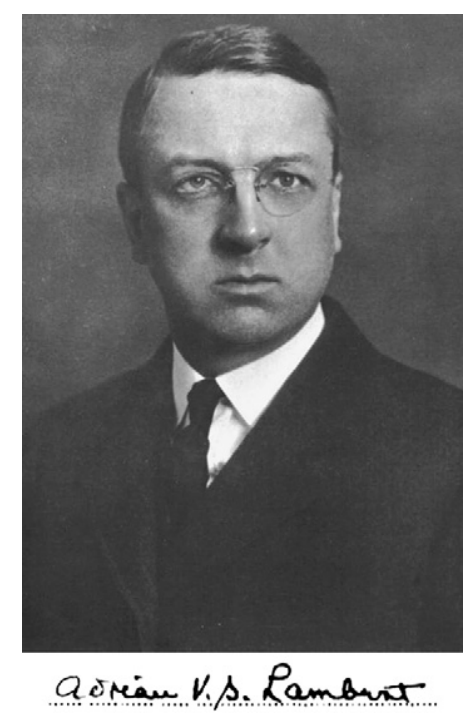

FIGURE 1. Adrian Van Sinderen Lambert.

rising to the position of clinical professor of surgery in 1921 and emeritus status in 1947), he also expanded his clinical practice to include being the chief of clinical surgery at the Vanderbilt Clinic (1908) and filling various positions at Presbyterian Hospital from 1912 through 1952. His affiliation with Bellevue Hospital lasted through 1946 , including 3 years as the director of chest surgery. During his career he also had appointments to New York LyingIn Hospital (later to become the Obstetrics and Gynecology Department of New York Hospital), Roosevelt Hospital, and Lincoln Hospital.

Dr Lambert's clinical practice included neurosurgery, general surgery, trauma surgery and the burgeoning field of thoracic surgery. He described the internal fixation of long bone fractures with aluminum plates and screws. He published a description of mediastinal pathways of infection that was based on experimental work. He took an active and important role in attempting to eradicate tuberculosis from New York City, modifying the technique of thoracoplasty and stressing the importance of removal of the first rib for effective collapse in treatment of pulmonary tuberculosis and tuberculous empyema, as well as emphasizing the role of phrenic nerve paralysis in the treatment. Along with Dr James Alexander Miller, he is credited with establishing the Chest Division at Bellevue Hospital (combining the tuberculosis service with the chest surgery service).

Lambert did not limit his medical interests to surgery. He recognized the importance of the anesthesiologist, especially in thoracic cases, and was instrumental in the 
recruitment of Emery Rovenstine, MD, to Bellevue Hospital. Rovenstine would go on to excel as a teacher and clinician and was among the founders of the American Society of Anesthesiologists. Additionally, Lambert supported and encouraged the training of nurse anesthetists at Presbyterian Hospital.

In 1917, Lambert was concurrently the acting head of surgery at Columbia and the head of surgery at Presbyterian Hospital (his brother Samuel Waldron was coincidently the Dean of the College of P\&S at that time, retiring in 1919). Thus, it is no surprise that he was one of the 25 local physicians invited by Willy Meyers, MD, to be a founding member of the New York Society for Thoracic Surgery. Shortly after its founding, Meyers invited leaders from outside of New York to form a national association, eventually to become the AATS. It should be noted that $70 \%$ of the original members of the AATS were from New York, including Lambert. The original intent of both groups was to develop an interest in the rapidly advancing field of thoracic surgery and to improve the training of medical students and doctors in this field. With World War I in progress and many senior surgeons being called off to serve their country, this became even more of a concern.

Despite (or perhaps because of) his extreme introversion, Lambert flourished as a teacher, clinician and leader. $\mathrm{He}$ avoided the limelight, however, refusing to have his photograph taken and shunning publicity, and he was not prolific in his publications. On June 7, 1940, Lambert delivered his presidential address at the AATS annual meeting in Cleveland, Ohio, entitled, "Etiology of Thoracic Thin-Walled Cysts." 1 This was a concise, informative, noncontroversial, and apolitical presentation that drew no attention to Lambert, his leadership of the AATS, or his many contributions to tho- racic surgery. His expertise in anatomy, embryology, and the scientific method was apparent as he led the audience through his discussion of the coelomic origin of pericardial cysts.

Lambert was a devoted father and husband. He had 4 children, Mary, Adrian, Jr, John Trumbull, and Ruth. Both of his sons became surgeons, and Adrian, Jr, was an active member of the AATS. Lambert's daughter Mary indirectly became a pioneer in medicine in 1908 as a neonate diagnosed with melena neonatorum. A lack of understanding of hemorrhagic disease of the neonate and the role of vitamin $\mathrm{K}$ meant that treatment options did not exist and Lambert was faced with the possibility of seeing his firstborn die. He spent the next 5 days researching the literature, and finally reasoned that a blood transfusion might benefit the baby. He approached Alexis Carrel, who at that time was performing vascular anastomoses on animals at the Rockefeller Institute, and Carrel with the assistance of George Brewer (and on the dining room table) isolated Lambert's left radial artery and anastomosed it to the right popliteal vein of the baby. After the transfusion, both vessels were ligated; Lambert apparently did not suffer any subsequent problems with his left hand. This became the first successful cure of this disease and indirectly played a part in ending legislative efforts in New York to ban vivisection.

As remembered by Frank Berry "[He had an extraordinarily orderly mind, a keen sense of humor, and a goodly store of sarcasm, which he used on his resident staff whenever he considered it necessary for their good." ${ }^{2}$

\section{References}

1. Lambert AV. Etiology of thin-walled thoracic cysts. J Thorac Surg. 1940;10: $1-7$.

2. Berry FB. In memoriam. Adrian VanSinderen Lambert 1872-1952. J Thorac Surg. 1953;25:543-4. 